\title{
Biosorption of chromium by the spores of Aspernigillus niger
}

\author{
Binqiao Ren \\ Institute of Advanced Technology, \\ Heilongjiang Academy of Sciences \\ Harbin, China \\ e-mail: renbinqiao@126.com
}

\author{
Yuting Zhang \\ Institute of Advanced Technology, \\ Heilongjiang Academy of Sciences \\ Harbin, China \\ e-mail: 454850609@qq.com
}

\section{Fengju Ouyang}

Institute of Advanced Technology, Heilongjiang Academy of Sciences

Harbin, China

e-mail:16468855@qq.com

\author{
Luyang Zhao \\ Institute of Advanced Technology, \\ Heilongjiang Academy of Sciences \\ Harbin, China \\ e-mail: 280353959@qq.com \\ Xiaochen Zhang \\ Institute of Advanced Technology, \\ Heilongjiang Academy of Sciences \\ Harbin, China \\ e-mail:779695850@qq.com \\ Hongwei Zhang* \\ Institute of Advanced Technology, \\ Heilongjiang Academy of Sciences \\ Harbin, China \\ e-mail: 1248131565@qq.com
}

\begin{abstract}
Quite a number of reports are available on metal binding capacity of different groups of microorganisms. However, reports on the fungal spores are quite inadequate. In the present study the effect of Aspergillums niger spores dosage, initial solution $\mathrm{pH}$ and adsorption temperature on the uptake of $\mathrm{Cr}$ (VI) by spores of A. niger from aqueous solution were investigated. Batch experiments were carried out in order to model and optimize the biosorption process. The influence of three parameters on the uptake of $\mathrm{Cr}$ (VI) was described. Optimum $\mathrm{Cr}$ (VI) uptake of $99.9 \mathrm{mg} / \mathrm{g} \mathrm{Cr}$ (VI) biomass was achieved at $\mathrm{pH} 2$, biomass dosage of $2 \mathrm{~g} / \mathrm{L}$ and $30 \circ$. The biosorption mechanism was also investigated by using Fourier transfer infrared (FT-IR) and Scanning electron microscope (SEM) analysis of biomass and $\mathrm{Cr}$ (VI) loaded biomass.
\end{abstract}

Keywords-Biosorption; Chromium; Aspernigillus niger; Spores.

\section{INTRODUCTION}

Uncontrolled discharge to the environment of wastewater containing heavy metal to the environment can be harmful to human, animals, plants and ecosystems [1]. Current treatment process, for metal containing wastewater are reported to exhibit reduce efficiency at low concentration. Increasing interest is observed in the application of biological materials for heavy metal removal from diluted, large volume solutions. Biosorption has become a method of choice as compared with traditional method such as precipitation, adsorption, coagulation, etc. as it is economically and environmentally more viable [2, 3].

Chromium is one of the major contaminant in the wastewaters of dyes and pigments, film and photography, galvanometric and electric, plating and electroplating, leather and mining industries [3]. This has led to the concern over the environmental effects of chromium present in surface wastewater and groundwater. Chromium removal using Aspergillums niger fungal biomass has been investigated by some researchers $[4,5]$. Park et al. [6] reported that the removal efficiency of total chromium decreased in the following order for biosorbent used in the study: S. cerebisiae $(44.2 \%)>$ P. chrysogenum $(40.3 \%)>$ A. niger $(29.3 \%)>\mathrm{R}$. oryzae $(23.5 \%)$. Fungus A. niger is reported to have less affinity to $\mathrm{Cr}$ (VI) compared to other fungal biomass, R. nigricans, R. arrhizus, and A. oryzae[4]. Fungi of Mucorales family (Mucor rouxii or R. arrhizus) were found to possess more chitaosan than A. niger[7]. However, spores of the A. niger biomass to improve the biosorption capacity has not yet been investigated. Spores of A. niger has potential been used for sorption of chromium from industrial wastewater. Therefore, this present work focuses on the aspect of chromium biosorption by A. niger spores.

\section{MATERIALS AND METHODS}

\section{A. Biosorbent preparation}

A Strain of fungal of A. niger used in this study obtained from maize straw. The strain was grown in Czapek's medium and maintained in nutrient agar at $4{ }^{\circ} \mathrm{C}$. The composition of growth medium was (grams per liter): sucrose (local market), 30; NaNO3 (Kermel), 3; KH2PO4 (Kermel), 1; MgSO4 (Kermel), 0.5; KCl(Kermel), 0.5; FeSO4,(Kermel),0.01; agar, 20. The medium was sterilized by autoclaving at pressure of 1.5 atm and 
temperature of $121{ }^{\circ} \mathrm{C}$ for $20 \mathrm{~min}$. The $\mathrm{pH}$ of the growth medium was adjusted to 5.0 by using $0.5 \mathrm{NH} 2 \mathrm{SO} 4$. Spores from established culture (6 to 7 days old) incubated on growth media agar at $30 \circ \mathrm{C}$ was used as biosorbent.

\section{B. Chromium solution and analysis}

Stock chromium solution of $1000 \mathrm{mg} / \mathrm{L}$ was prepared by dissolving $2.828 \mathrm{~g}$ of potassium dichromate in $1 \mathrm{~L}$ of deionized water. The working chromium solution $(100 \mathrm{mg} / \mathrm{L})$ was prepared by diluting the stock chromium solution. The total chromium concentration in the solution was determined by atomic absorption spectroscopy using a (Persee TAS-990) atomic absorption spectrometer [8].

\section{Metal uptake $(q)$}

Uptake of metal ions was calculated from a metal mass balance yielding:

$$
q=\frac{V\left(C_{i}-C_{f}\right)}{m}
$$

where $\mathrm{q}$ is $\mathrm{mg}$ metal ions per $\mathrm{g}$ dry biosorbent; $\mathrm{V}$ is the reaction volume (1), $\mathrm{Ci}$ and $\mathrm{Cf}$ are the initial and residual metal concentrations $(\mathrm{mg} / \mathrm{L})$, respectively, and $\mathrm{m}$ is the amount of dry biosorbent $(\mathrm{g})$.

\section{Effect of adsorbent weight}

To study the effect of dosage of A.niger spores, the adsorbent doses range from $2 \mathrm{~g} / \mathrm{L}-10 \mathrm{~g} / \mathrm{L}$, with increments of $0.5 \mathrm{~g} / \mathrm{L}$, The sample were shaken $3 \mathrm{~h}$ at $150 \mathrm{rpm}$ at room temperature $(22 \pm 2 \circ \mathrm{C})$.

\section{E. Effect of $p H$}

The effect of $\mathrm{pH}$ on the biosorption of chromium was investigated by contacting the spores biomass $(2 \mathrm{~g} / \mathrm{L})$ in the $\mathrm{pH}$ range of 2.0-5.0, with increments of 1 . The $\mathrm{pH}$ was kept constant during the study. The samples were shaken 3 $\mathrm{h}$ at $150 \mathrm{rpm}$ at room temperature $\left(22 \pm 2{ }^{\circ} \mathrm{C}\right)$.

\section{F. Effect of temperature}

The effect of temperature on the biosorption of chromium was investigated by contacting the spores biomass $(\mathrm{g} / \mathrm{L})$ in the temperature range of $5 \circ \mathrm{C}-35{ }^{\circ} \mathrm{C}$, with increments of $5{ }^{\circ} \mathrm{C}$.

\section{G. FT-IR analysis of biosorbent}

For the Fourier transform infrared spectroscopy (FT-IR) study, samples of $1 \mathrm{mg}$ of the strained cells before and after the metal biosorption, respectively, were obtained with $300 \mathrm{mg}$ of $\mathrm{KBr}$ to prepare translucent sample disks [9]. Infrared spectra were recorded using a Lambada FTIR7600 spectrometer.

\section{H. Scanning electron microscope (SEM)}

SEM was used to study the outer surface, microporosity and pore size of the non-viable A.niger spores. The samples were dried and viewed by microscope (Hitachi-S4800). Finally, the SEM images were analyzed at 25000 magnifications.

\section{RESULTS AND DISCUSSION}

\section{A. Effect of adsorbent weight}

The effect of adsorbent weight $(\mathrm{g} / \mathrm{L})$ on the adsorption efficiency is shown on Fig .1. Adsorption experiments were carried out at different biosorbent doses ranging from $2 \mathrm{~g} / \mathrm{L}$ to $10 \mathrm{~g} / \mathrm{L}$ in chromium solution. It was observed as a general trend that there is an increase of the removal of heavy metal ions with increase in adsorbent weight .The maximum removal of the most heavy metal ions was attained at an adsorbent dose of $2 \mathrm{~g} / \mathrm{L}$ with no further significant increase in the removal of heavy metal ions at higher biosorbent concentration tested was observed.

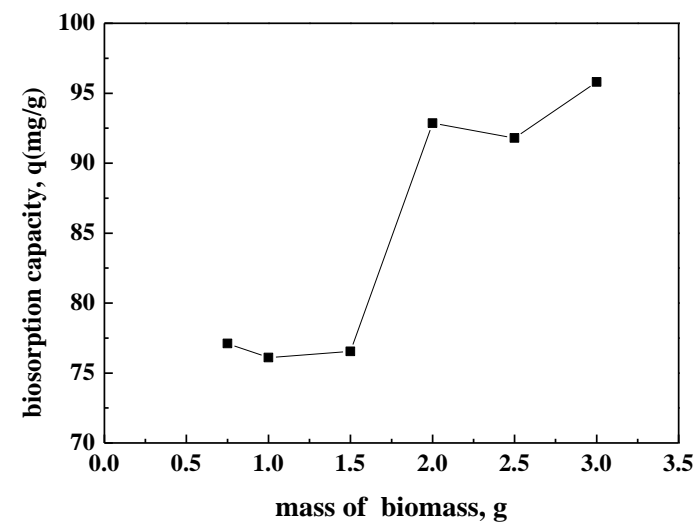

Figure 1. The effect of mass of biomass on biosorption of chromium

\section{B. Effect of $p H$}

The highest chromium removal efficiency was observed at $\mathrm{pH} 2.0$, and removal efficiency decreased with an increase in $\mathrm{pH}$ (Fig .2). A similar trend has been reported for a variety of biosorbents[10]. As the $\mathrm{pH}$ is lowered, the surface of the spores of A.niger with positive charge, which will provide strong affinity to the negative charge $\mathrm{Cr}$ (VI) complex ions in the solution. Hence, biosorption increase with an increase in the acidity of the solution. But as the $\mathrm{pH}$ increase, the concentration of $\mathrm{OH}$ ions increase and overall charge on the surface of spores will be negative. This cause a hindrance to the biosorption of negatively charged chromium ions such as Cr2O72-, CrO42- resulting in a decrease of biosorption of chromium at higher $\mathrm{pH}$ levels $[11,12]$. Hence, it can be concluded that electrostatic attraction plays an important role in this biosorption process. 


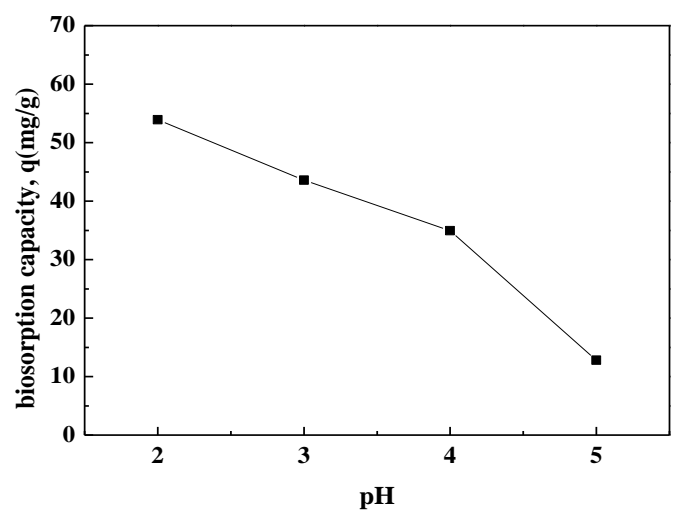

Figure 2. The effect of $\mathrm{pH}$ on biosorption of chromium

\section{Effect of temperature}

The results on effect of temperature indicated that the maximum uptake of $\mathrm{Cr}$ (VI) was observed at 30. The increase in temperature increased the $\mathrm{Cr}$ (VI) biosorption rate.

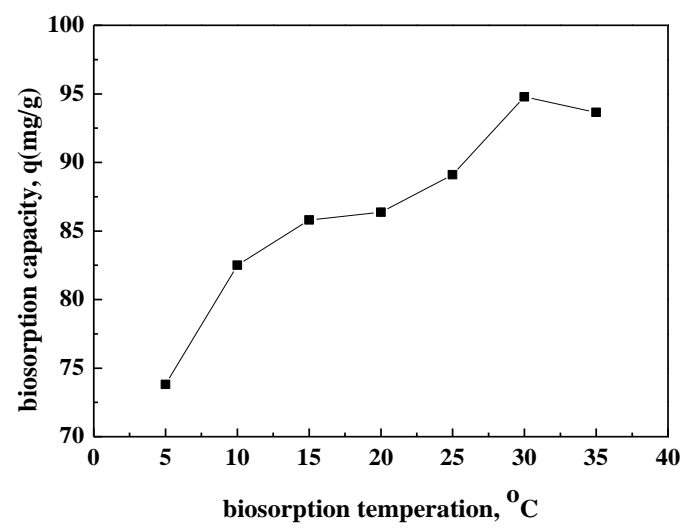

Figure 3. The effect of mass of biomass on biosorption of chromium

\section{Biosorption mechanism: The FT-IR analysis}

The infrared spectra of autoclaved biomass, and biomass loaded with chromium are shown in Fig .4. The figure shows a number of absorption peaks, which indicates the complex structure of the examined biomass. The IR spectrum of A.niger spores biomasses with chromium was similar to the IR spectrum of the autoclaved biomass. It didn't show any characteristic omission or addition of peaks, indicating the structure of the biomass with chromium didn't change. The FT-IR bands show five major IR absorption bands: broad amines and amides band (N-H stretching), amide $(\mathrm{C}=\mathrm{O})$ stretching band, amides $(\mathrm{N}-$ $\mathrm{H}$ bending), carbonyl group (-CO) stretching band and fingerprint band. The most remarkable difference between the two spectra is at intensity of $3000-3600 \mathrm{~cm}-1$ representing amines and amides band (-NH) group stretching, and at intensity of $1600-1700 \mathrm{~cm}-1$ representing amide $(-\mathrm{C}=\mathrm{O})$ stretching. The intensity of amino and amide bands of $\mathrm{Cr}$ (VI) sorbed biomass was much greater than the biomass without chromium.

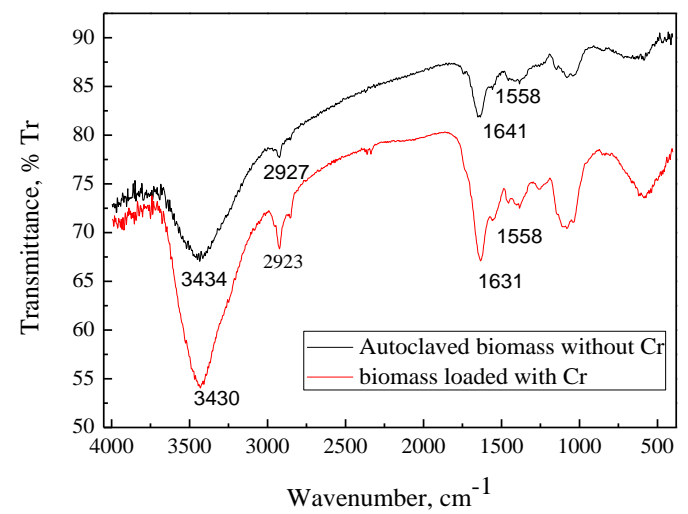

Figure 4. IR spectrum of autoclaved biomass without $\mathrm{Cr}$ (VI), biomass loaded with $\mathrm{Cr}(\mathrm{VI})$

\section{E. Scanning electron microscope (SEM) analysis}

Fig .5 show scanning electron microscope (SEM) observation of surface morphology for autoclaved biomass and biomass loaded with chromium. The surface morphology of autoclaved biomass and biomass loaded with chromium may exhibit microstructure porosity. Autoclaved biomass(Fig .5a) display smooth surface morphology and much accessible space within glucanchitin skeleton, hence allowing more heavy metal ions chelation at the surface $[13,14]$. It can be seen that the space and pores of biomass loaded with chromium obviously decreased (Fig .5b). These A. niger spores with clean surface and high porosity may have application as biosorbent for heavy metal removal from wastewater effluents.

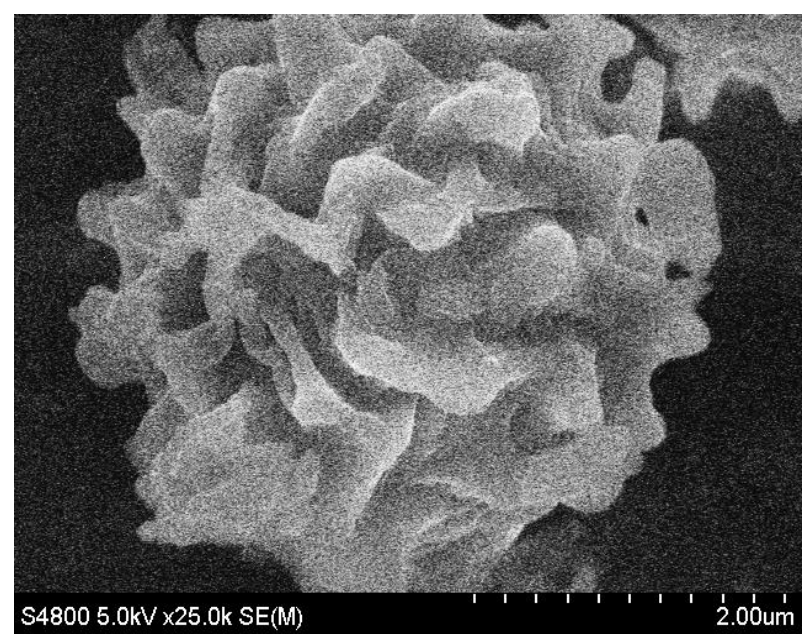

Figure 5a. Autoclaved spores of A. niger 


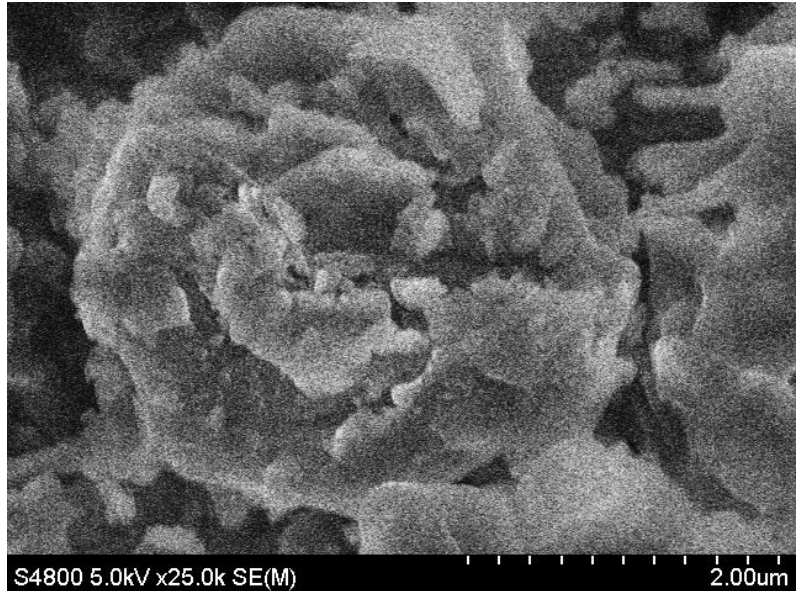

Figure 5b. Spores of A. niger loaded with chromium Scanning electron microscope (SEM )of spores with and without $\mathrm{Cr}(\mathrm{VI})$

\section{CONCLUSION}

A. niger spores is suited for removing $\mathrm{Cr}(\mathrm{VI})$ from aqueous solution due to its high capacity of biosorption. The initial solution $\mathrm{pH}$, biomass dosage and temperature significantly influence $\mathrm{Cr}$ (VI) uptake while maximum adsorption was found to be at $\mathrm{pH} 2,2.0 \mathrm{~g} / \mathrm{L}$ and 30 , respectively. The uptake capacity of $\mathrm{Cr}(\mathrm{VI})$ increased with decrease in $\mathrm{pH}$ and increase in temperature. The maximum uptake capacity by A. niger biomass was obtained at 99.9 $\mathrm{mg} \mathrm{Cr}(\mathrm{VI}) / \mathrm{g}$ biomass. The present study indicates that spores of A. niger could be used as an efficient biosorbent for removal of $\mathrm{Cr}$ (VI) from wastewater. In the study, the biomass was justified on the basis of the Fourier transfer infrared (FT-IR) analysis. The interaction of A. niger spores biomass with $\mathrm{Cr}$ (VI) was characterized using FTIR spectra. The FT-IR analysis implied that the interaction between chromium and N-containing bioligands on the cell surface of A. niger spores. Studies conducted using synthetic metal ions solution, revealed the practical application of the A. niger spores biomass as a potential biosorbent for sequestration of $\mathrm{Cr}$ (VI) from industrial effluents as well as from contaminated groundwater.

\section{ACKNOWLEDGMENTS:}

The study was funded by a research grant to the first author by the Science and Technology Department of Heilongjiang Province (Grant number GC13C304)

\section{REFERENCES:}

[1] M.Y. Pamukoglu, F. Kargi, Batch kinetics and isotherms for biosorption of copper(II) ions onto pre-treated powdered waste sludge (PWS), J. Hazard.Mater., 138 (2006) 479-484.

[2] Y. Khambhaty, K. Mody, S. Basha, B. Jha, Kinetics, equilibrium and thermodynamic studies on biosorption of hexavalent chromium by dead fungal biomass of marine Aspergillus niger, Chemical Engineering Journal, 145 (2009) 489-495.

[3] D.P. Mungasavalli, T. Viraraghavan, Y.-C. Jin, Biosorption of chromium from aqueous solutions by pretreated Aspergillus niger: Batch and column studies, Colloids and Surfaces A Physicochemical and Engineering Aspects, 301 (2007) 214-223.

[4] R.S. Bai, T.E. Abraham, Studies of biosorption of chromium(VI) by dead fungal biomass, J. Sci. Ind. Res., (1998) 821-824.

[5] K.C. Sekhar, S. Subramanian, J.M. Modak, K.A. Natarajan, Removal of metal ions using an industrial biomass with reference to environmental control, International Journal of Mineral Processing, 53 (1998) 107-120.

[6] D. Park, Y.-S. Yun, J.M. Park, Use of dead fungal biomass for the detoxification of hexavalent chromium: screening and kinetics, Process Biochemistry, 40 (2005) 2559-2565.

[7] M. Oves, M.S. Khan, A. Zaidi, Biosorption of heavy metals by Bacillus thuringiensis strain OSM29 originating from industria effluent contaminated north Indian soil, Saudi Journal of Biological Sciences, 20 (2013) 121-129.

[8] Standard Methods for the Examination ofWater andWastewater, 20th ed.,, American Public Health Association Washington, DC, USA, (1998).

[9] Q. Hu, H. Qi, Bai,, D. Z., M., , J. Zeng, F. Zhang, H. Zhang, Biosorption ofcadmium by a $\mathrm{Cd} 2+$ hyperresistant Bacillus cereus strain HQ-1 newly isolated from a lead and zinc mine, World $\mathrm{J}$. Microbiol. Biot., 23 (2007) 971-976.

[10] S. Tunali, I. Kiran, T. Akar, Chromium(VI) biosorption characteristics of Neurospora crassa fungal biomass, Miner. Eng, (2005) 681-689.

[11] N. Tewari, P. Vasudevan, B.K. Guha, Study of biosorption of Cr(VI) by Mucor hiemalis, Biochem. Eng. J., 23 (2005) 185-192.

[12] H. Niu, B. Volesky, Characteristics of anionic metal species biosorption with waste crab shells, Hydrometallurgy, (2003) 209215.

[13] E. Luef, T. Prey, C.P. Kubicek, Biosorption of zinc by fungal mycelial wastes, Applied Microbiology and Biotechnology, 34 (1991) 688-692

[14] E.-S.M., El-Morsy, Cunninghamella echinulata a new biosorbent of metal ions from polluted water in Egypt, Mycologia, (2004) 11831189. 